Review

\title{
Aspects of early arthritis What determines the evolution of early undifferentiated arthritis and rheumatoid arthritis? An update from the Norfolk Arthritis Register
}

\author{
Deborah PM Symmons and Alan J Silman
}

arc Epidemiology Unit, University of Manchester, UK

Corresponding author: Deborah PM Symmons, deborah.symmons@manchester.ac.uk

Published: 14 June 2006

This article is online at http://arthritis-research.com/content/8/4/214

(c) 2006 BioMed Central Ltd
Arthritis Research \& Therapy 2006, 8:214 (doi:10.1186/ar1979)

for DNA extraction. Serum is also stored. The patient completes a Health Assessment Questionnaire (HAQ) [2] adapted for British use [3].

Over 3500 patients with recent onset inflammatory polyarthritis (IP have been recruited by the Norfolk Arthritis Register (NOAR) since 1990. Longitudinal data from this cohort have been used to examine the prevalence and predictors of remission, functional disability, radiological outcome, cardiovascular mortality and co-morbidity and the development of non-Hodgkin's lymphoma. Rheumatoid factor titre, high baseline $\mathrm{C}$-reactive protein and high baseline $\mathrm{HAQ}$ score are all predictors of a poor outcome. There is a strong association between possession of the shared epitope and the development of erosions. Patients who satisfy the American College of Rheumatology criteria for rheumatoid arthritis (RA) have a worse prognosis than those who do not. However, it appears that these patients are a poorly defined subset of all those with IP rather than having an entirely separate disease entity. New statistical techniques offer exciting possibilities for using longitudinal datasets such as NOAR to explore the long-term effects of treatment in IP and RA.

\section{Introduction}

The Norfolk Arthritis Register (NOAR) was established during 1989. By the beginning of 1990, all the general practitioners in what was then the Norwich Health Authority had been visited and asked to participate. From 1 January 1990, the general practitioners and local rheumatologists referred to NOAR all adults (aged $\geq 16$ ) whom they saw with two or more swollen joints, lasting for 4 weeks or more, with an onset of symptoms after 1 January 1989.

After receiving a notification, NOAR sends one of its team of metrologists (research nurses) to the patient's home to take a standardised history and to examine the joints for tenderness, swelling and deformity/damage [1]. In addition, a blood sample is taken for rheumatoid factor (RF) measurement and
Over 3,500 patients have now been recruited by NOAR. Although the 15 years since NOAR was established have seen dramatic changes in the range of disease-modifying antirheumatic drugs (DMARDS) that are available and the way in which they are used, one of the fundamental questions that NOAR was set up to address remains highly pertinent. This is the question of whether it is possible to predict, early in the course of the disease, a patient's natural history.

This question becomes ever more relevant as it is now well accepted that patients who are destined to have persistent disabling arthritis should start DMARD therapy as soon as possible (preferably within the first 12 weeks of disease). Patients who fail to respond to DMARD therapy should be moved on to a biologic agent. Set against this is the fact that many patients with recent-onset arthritis do well. In some patients, the arthritis resolves completely and many patients never develop any significant disability or radiological erosions. It would be exposing these patients to unnecessary risk to give them intensive DMARD therapy or even biologic therapy. On the other hand, some patients do very badly and fail to respond to one DMARD after another. It would clearly be useful to be able to predict both a poor prognosis and response to individual agents so that the right drug can be given to the right patient - 'designer therapy'.

Predictors (or determinants) of outcome can be grouped into person-specific factors - age, gender, socioeconomic status,

$\mathrm{ACR}=$ American College of Rheumatology; anti-CCP = anticyclic citrullinated peptide; $\mathrm{CRP}=\mathrm{C}$-reactive protein; $\mathrm{DAS}=$ disease activity score; DMARD = disease-modifying antirheumatic drug; ELISA= enzyme-linked immunosorbent assay; HAQ = Health Assessment Questionnaire; IP = inflammatory polyarthritis; NOAR = Norfolk Arthritis Register; RA = rheumatoid arthritis; RF = rheumatoid factor; SE = shared epitope. 
lifestyle (e.g. smoking, exercise, alcohol, diet), psychological factors (e.g. coping strategies), genetic make-up - diseasespecific factors (e.g. severity of arthritis, comorbidity) and treatment-specific factors (e.g. drug and nondrug modalities, adverse events, patient adherence to prescribed treatment). All these factors interact and the prediction of outcome for the individual patient (as opposed to the average patient) remains problematic.

\section{Classification of inflammatory polyarthritis and rheumatoid arthritis}

When NOAR was initially established, its aim was to study the natural history of rheumatoid arthritis (RA). The net was deliberately cast wide at the time of recruitment as it was always clear that patients would not satisfy classification criteria for RA within a few days or weeks of developing arthritis. NOAR was established fairly soon after the publication of the 1987 American Rheumatism Association, now the American College of Rheumatology (ACR), criteria for RA [4]. In the early years, therefore, NOAR investigators as well as others were learning the strengths and weaknesses of these criteria (which had been derived predominantly from current attenders to tertiary care with long-standing disease).

One finding was that the criteria were not robust - patients might satisfy the criteria on one visit and not on another. We decided that the appropriate method was to apply the criteria cumulatively. It took many patients up to 5 years to satisfy the criteria [5]. What is more, there was no clear division between those patients who did satisfy the ACR criteria and those patients who did not satisfy the criteria with regards to their ultimate prognosis. While those who satisfied the criteria - and particularly those who were RF-positive - tended to have a worse prognosis, many patients who did not satisfy the criteria also had a poor outcome. We have therefore tended increasingly to report the results of our whole inflammatory polyarthritis (IP) cohort and then to present, separately, the outcome of those patients who can be classified as having RA. We feel that this is more informative and also that this is a more generalisable cohort in whom to develop prognostic models.

The time is probably now right to reconsider whether classification criteria for 'early RA' can be developed. It does appear that IP patients with autoantibodies (either RF or anticyclic citrullinated peptide (anti-CCP) antibodies) may have a different aetiology and a different response to treatment from patients who are autoantibody negative $[6,7]$. It may therefore be more helpful in future to separate these two groups rather than to leave them combined in the single entity of IP. There is a tendency always to focus on the subgroup of patients with the worst prognosis (e.g. those who satisfy the ACR criteria or those who are autoantibodypositive). It is important to emphasise, however, that even those patients in the better prognosis group may have a poor outcome with regards to disability and deformity. It is possible that none of the current DMARDs or perhaps even the biologic agents are effective in the better prognosis group and that we have to start from scratch in establishing the best way of managing patients with mild disease.

\section{Outcome following the onset of inflammatory polyarthritis}

NOAR dataset has been used to address questions about the occurrence of a variety of outcomes at 1 year, 3 years, 5 years and now 10 years, as well as predictors of these outcomes [8]

\section{Remission}

It is important to be able to predict which patients will go into remission; that is, which patients will have no evidence of any inflammatory activity in their joints while they are off treatment. Persistence is the opposite of remission. There are problems in the literature regarding the definition of remission and the resolution of IP. Both require a robust method of measuring disease activity.

The first systematic approach to the definition of remission in RA was carried out on behalf of the American Rheumatism Association in 1981 [9]. The development of the disease activity score (DAS) [10] and its daughter (DAS-28) [11] has more recently helped to clarify the situation. Van Gestel and colleagues assessed patients both with a DAS-28 and with the American Rheumatism Association remission criteria, and estimated that a DAS-28 less than 2.6 could be regarded as remission [12].

In NOAR, however, we began to look at remission before the publication of the DAS-28 work. We therefore developed our own definition of 'remission off treatment', being no soft tissue joint swelling and the patient not having been treated with DMARDs or steroids within the previous 3 months. 'Treatment-induced remission' had the same definition except that patients could be receiving DMARDs. At 3 years, 32\% of NOAR IP patients were in remission, as were $18 \%$ of NOAR patients in the RA subgroup [8]. Only $11 \%$ of the IP patients were in remission at 1 year, 2 years and 3 years, and so could be regarded as being in complete resolution of their disease. In a multiple logistic regression analysis, three baseline variables (RF negativity, fewer than six tender joints and the absence of ankle swelling) were found to be important independent predictors of remission. The model only had an explained variance of $17 \%$, however, and clearly could not be used in the routine clinical setting [8].

It is possible that the patient's production of endogenous corticosteroids may influence IP persistence. Individuals who produce high levels of endogenous steroid may 'switch off' their arthritis, whereas those whose steroid production is lower may have persistent disease. This level of response is probably genetically determined. The early administration of 
intraarticular or intramuscular steroids in this very early phase may be of lasting benefit [13].

We then focused on trying to predict those individuals who would have a poor outcome. It is important to emphasise, however, that many patients who did not go into complete remission nevertheless had a relatively good outcome.

\section{Functional disability}

Functional disability measured using the $\mathrm{HAQ}$ has proved to be one of the most reliable outcome measures for both IP and RA. Many researchers have found that the HAQ score predicts many features of the patient's subsequent disease course, including mortality [14]. Patients in NOAR complete a $\mathrm{HAQ}$ at baseline and at years 1, 2, 3, 4, 5, 7, 10, 12 and 15. The proportion of patients with a $\mathrm{HAQ}$ score $\geq 1.0$ continues to rise as time goes by, from $29 \%$ at 1 year, $44 \%$ at 3 years, $47 \%$ at 5 years to $49 \%$ at 10 years. Most of the disability accrues in the first 3 years - but it has to be remembered that the $\mathrm{HAQ}$ score can only be measured in survivors, and the most disabled patients are more likely to die or be lost to follow-up.

We have found that the 1-year HAQ score is a better predictor of subsequent outcome than the baseline HAQ score [15]. This offers hope for the early modification of what might otherwise have been a poor outcome. The key risk factors for the development of moderate disability (HAQ score $\geq 1.0$ ) at 5 years are being female, aged over 64 at baseline, the number of damaged joints, RF positivity and the presence of nodules at baseline [16] A similar set of variables had been found to predict a $\mathrm{HAQ}$ score $>1.0$ at 3 years [8].

\section{Radiological outcome}

The rules for conducting X-ray scans in NOAR have varied over the course of the past 15 years. X-rays were initially not carried out at baseline. The assumption at that time was that patients would be presenting early, before erosions could have developed, and it would therefore be unethical to expose them to radiation. As the register grew, however, patients had longer in which to present (the requirement to have an onset since 1 January 1989 has only recently been moved forward to 1 January 2000). X-rays were initially performed in NOAR at the first and/or second anniversary of presentation if a patient already satisfied the ACR criteria for $\mathrm{RA}$, or if the presence of erosions would lead the patient to satisfy these criteria. All patients were X-rayed at the fifth anniversary of presentation.

More recently we have performed baseline X-ray scans in a series of patients presenting from 2000 onwards. We therefore have some information about predictors of erosions at presentation and 1 year, 3 years and 5 years after symptom onset. Erosions are much more common at baseline in older patients than in younger patients [17]. We were able to show that, although the peak incidence of first erosions is within the first 24 months of disease, individuals who are nonerosive at 24 months have an ongoing risk of becoming erosive, which does not decline with time [18].

The baseline C-reactive protein (CRP) level was a strong predictor of the degree of erosive damage on both the 1-year and 5-year anniversary films. An RF titre greater than 1 in 160 was the strongest predictor of X-ray progression [19].

There has been much recent interest in the role of anti-CCP autoantibodies in predicting outcome in RA and IP. Anti-CCP antibodies are present in around $55 \%$ of patients with early RA and have been found to predict the development and progression of erosions within the first 2 years of disease [20]. Anti-CCP antibodies are much more specific for RA than RF. We found the predictive value of anti-CCP antibodies, measured using a second-generation ELISA assay, in 198 individuals with radiographs of their hands and feet taken within 12 months of symptom onset to be higher than the predictive value of RF with respect to both the development and progression of erosions [21]. The measurement of anti-CCP antibodies appeared to be particularly useful as a predictor of radiological outcome in those who are RF-negative.

\section{Cardiovascular mortality and comorbidity}

There is increasing interest in the literature regarding the link between inflammatory musculoskeletal conditions and accelerated atherosclerosis. This link is evident even in IP patients in the early years of disease. Among the first 1,235 subjects recruited to NOAR up to the end of 1994 and followed for a median of 8 years, the standardised mortality ratios in RF-positive patients were 1.5 for men and 1.4 for women. All the excess deaths in seropositive women were due to cardiovascular causes. The standardised mortality ratio for cardiovascular mortality in this group of women was 2.0 (95\% confidence interval, 1.2-3.3) [22].

The baseline CRP level was a strong predictor of future cardiovascular mortality, thus supporting the hypothesis that the increased risk of coronary heart disease in RA and IP is related to the burden of inflammation [23]. Perhaps surprisingly, smoking - either ever or current - was not a predictor of cardiovascular mortality, but this might reflect the dominant effect of the inflammation in this population. Although based on cross-sectional data, we have also noted that the prevalence of angina as detected by the Rose angina questionnaire increases with disease duration [24].

\section{Non-Hodgkin's lymphoma}

Although there was no evidence of any overall increased risk of cancer in the early years of IP and RA in NOAR, there was a definite increased risk of developing non-Hodgkin's lymphoma (standardised incidence ratio, 2.4; 95\% confidence interval, 1.2-4.2). The standardised incidence ratio was even higher in the subset of patients with RA $(2.9 ; 95 \%$ 
confidence interval, 1.3-5.6). Predictors of developing nonHodgkin's lymphoma included RF, HAQ score $\geq 1$ and the presence of erosions [25].

\section{Response to treatment}

It is clear that outcome in an observational cohort such as NOAR is related in part to the treatment received. Understanding the role of laboratory or clinical predictors in explaining outcome requires adjustment for the probable phenomenon that the more severe the disease, the more intensive the therapy. The question can conversely be turned on its head, and the data can be used to address questions of treatment efficacy. It is difficult to explore the effects of treatment in longitudinal observational cohorts such as NOAR because, as implied earlier, the decision to treat is not random. Unless the treatment is so effective as to negate all the effects of disease severity, then those patients who are treated are likely to have a worse outcome than those whose disease was so mild as not to warrant therapy.

The propensity score and marginal structural modelling offer two ways of adjusting for the baseline severity, which influences the physician's decision to start treatment. We have used the propensity score method to demonstrate the benefit of starting treatment within 6 months of symptom onset on functional outcome [26] and on radiological outcome [27].

With the advent of new treatment strategies and more effective (but also expensive) treatments, it becomes ever more important to try and predict whether or not a patient will respond to a particular medication. There are a number of variables that may influence treatment response. These include genetic factors, both genes that affect the severity of the disease and genes that affect the handling of the drug. Then there are psychosocial factors such as adherence to and expectations of therapy outcome. Finally, there are aspects related to the underlying disease and associated comorbidities. Those patients who are RF-positive or are shared epitope (SE)-positive may be more or less likely to response to certain DMARDs.

We found that it was not possible to predict the response to methotrexate (defined as remaining on the drug with no additional DMARD starts at 1 year) with any useful degree of accuracy using baseline clinical and demographic variables [28]. The only predictor of discontinuing methotrexate was a high baseline HAQ score. Work is now focusing on identifying genetic predictors of response by looking at various genes along the metabolic pathway of methotrexate.

\section{Genetic predictors of outcome}

We have had only limited success in predicting outcome robustly from routinely collected clinical and laboratory variables. It seems probable that constitutional predictors such as genetic factors play an important role, and they are therefore an obvious target to study.
It is well recognised that the region of HLADRB1 known as the SE is the strongest genetic predictor of outcome in RA. In NOAR, we found no evidence that the SE (or any particular SE-bearing allele) had any influence on disease remission or persistence. There was a weak influence of the SE on the development of moderate disability ( $\mathrm{HAQ}$ score >1.0) confined to individuals who were RF-negative. The association between the SE and the development of radiological erosions was much stronger. In particular, individuals who were homozygous for HLADRB1*0404 were four times more likely to develop erosions than those who were SE-negative (odds ratio, 4.2; 95\% confidence interval, 2.0-88.5) [29].

NOAR patients who were homozygous for the SE similarly had increased all-cause mortality and cardiovascular mortality over the first 8 years of disease [30].

No association was found between individual polymorphisms of the tumour necrosis factor gene [31] or the mannose binding lectin gene [32] and the development of radiological erosions at 5 years.

Citrullination, the process underlying the development of antiCCP antibodies, is mediated by the enzyme peptidylarginine deiminase - of which there are five isoforms. A Japanese group reported an association between the PAD/4 gene and RA [33]. We were not able, however, to find any association between polymorphisms of the PADI4 gene and the presence, the extent or the progression of erosions or the development of anti-CCP antibodies [34]. Further publications have confirmed an association between PAD/4 and RA in another Japanese population [35], in a South Korean population [36] and in a North America population [37], but not in a French population [38] or a Swedish population [37]. This may reflect different genetic associations in different ethnic groups.

\section{Conclusion}

Certain predictors recur as we look at a variety of outcomes. These include RF positivity, a high baseline CRP and a high baseline HAQ score. With regards to the CRP and $\mathrm{HAQ}$, it seems probable that the baseline values are important predictors of the later course of the disease because they are surrogates for the cumulative disease activity and disease severity. Those patients whose disease starts badly tend to continue to do badly. We have shown the benefits of starting disease-modifying therapy early in the course of the disease. The fact that a greater proportion of patients are now treated early and with more effective treatment combinations and regimes leads us to hope that we will find the 5-year outcome of patients with an onset of disease since 2000 to be better than that in those patients with an onset in 1990. However, some patients continue to present late to medical care and not all patients respond even to the most modern and aggressive of regimes. It is important, therefore, to continue to enrol and study patients so that we can understand more about this disabling disease, which shortens life expectancy. 
This review is part of a series on

Aspects of early arthritis

edited by Josef Smolen.

Other articles in this series can be found at

http://arthritis-research.com/articles/

review-series.asp?series=ar_Early

\section{Competing interests}

The authors declare that they have no competing interests.

\section{References}

1. Bunn DK, Shepstone L, Galpin LM, Wiles NJ, Symmons DP: The NOAR Damaged Joint Count (NOAR-DJC): a clinical measure for assessing articular damage in patients with early inflammatory polyarthritis including rheumatoid arthritis. Rheumato/ogy (Oxford) 2004, 43:1519-1525.

2. Fries JF, Spitz P, Kraines RG, Holman HR: Measurement of patient outcome in arthritis. Arthritis Rheum 1980, 23:137-145.

3. Kirwan JR, Reeback JS: Stanford Health Assessment questionnaire modified to assess disability in British patients with rheumatoid arthritis. Br J Rheumato/ 1986, 25:206-209.

4. Arnett FC, Edworthy SM, Bloch DA, McShane DJ, Fries JF, Cooper NS, Healey LA, Kaplan SR, Liang MH, Luthra HS, et al:: The American Rheumatism Association 1987 revised criteria for the classification of rheumatoid arthritis. Arthritis Rheum 1988, 31:315-324.

5. Wiles N, Symmons DPM, Harrison B, Barrett E, Barrett JH, Scott DGI, Silman AJ: Estimating the incidence of rheumatoid arthritis: trying to hit a moving target? Arthritis Rheum 1999, 42: 1339-1346.

6. Huizinga TW, Amos $\mathrm{Cl}$, van der Helm-van Mil AH, Chen W, van Gaalen FA, Jawaheer D, Schreuder GM, Wener M, Breedveld FC, Ahmad N, et al:: Refining the complex rheumatoid arthritis phenotype based on specificity of the HLA-DRB1 shared epitope for antibodies to citrullinated proteins. Arthritis Rheum 2005, 52:3433-3438.

7. Klareskog L, Stolt $P$, Lundberg K, Kallberg H, Bengtsson C, Grunewald J, Ronnelid J, Harris HE, Ulfgren AK, RantapaaDahlqvist $\mathrm{S}$, et al.: A new model for an etiology of rheumatoid arthritis. Arthritis Rheum 2006, 54:38-46.

8. Harrison B, Symmons D: Early inflammatory polyarthritis: results from the Norfolk Arthritis Register with a review of the literature. II. Outcome at three years. Rheumatology (Oxford) 2000, 39:939-949.

9. Pinals RS, Masi AT, Larsen RA: Preliminary criteria for clinical remission in rheumatoid arthritis. Arthritis Rheum 1981, 24: 1308-1315.

10. van der Heijde DM, van Riel PL, van Leeuwen MA, van't Hof MA, van Rijswijk $\mathrm{MH}$, van de Putte LB: Older versus younger onset rheumatoid arthritis: results at onset and after 2 years of a prospective followup study of early rheumatoid arthritis. J Rheumatol 1991, 18:1285-1289.

11. Prevoo ML, 't Hof MA, Kuper $\mathrm{HH}$, van Leeuwen MA, van de Putte LB, van Riel PL: Modified disease activity scores that include twenty-eight-joint counts. Development and validation in a prospective longitudinal study of patients with rheumatoid arthritis. Arthritis Rheum 1995, 38:44-48.

12. van Gestel AM, Haagsma CJ, van Riel PL: Validation of rheumatoid arthritis improvement criteria that include simplified joint counts. Arthritis Rheum 1998, 41:1845-1850.

13. Green M, Marzo-Ortega H, Wakefield RJ, Astin P, Proudman S, Conaghan PG, Hordon L, Emery P: Predictors of outcome in patients with oligoarthritis: results of a protocol of intraarticular corticosteroids to all clinically active joints. Arthritis Rheum 2001, 44:1177-1783.

14. Pincus T, Callahan LF: Formal education as a marker for increased mortality and morbidity in rheumatoid arthritis. J Chronic Dis 1985, 38:973-984.

15. Wiles NJ, Dunn G, Barrett EM, Harrison BJ, Silman AJ, Symmons DP: One year followup variables predict disability 5 years after presentation with inflammatory polyarthritis with greater accuracy than at baseline. J Rheumatol 2000, 27:2360-2366.

16. Wiles N, Dunn G, Barrett E, Silman A, Symmons D: Associations between demographic and disease-related variables and disability over the first five years of inflammatory polyarthritis: a longitudinal analysis using generalized estimating equations. $J$ Clin Epidemiol 2000, 53:988-996.

17. Bukhari M, Lunt M, Scott DGI, Symmons D, Silman A: Increasing age at symptom onset is strongly associated with worse radiologic damage both at presentation and follow-up in an inception cohort of patients with inflammatory polyarthritis [abstract]. Arthritis Rheum 2005, 52(Suppl):S451.

18. Bukhari M, Harrison B, Lunt M, Scott DG, Symmons DP, Silman AJ: Time to first occurrence of erosions in inflammatory polyarthritis: results from a prospective community-based study. Arthritis Rheum 2001, 44:1248-1253.

19. Bukhari M, Lunt M, Harrison BJ, Scott DG, Symmons DP, Silman $\mathrm{AJ}$ : Rheumatoid factor is the major predictor of increasing severity of radiographic erosions in rheumatoid arthritis: results from the Norfolk Arthritis Register Study, a large inception cohort. Arthritis Rheum 2002, 46:906-912.

20. Forslind K, Ahlmen M, Eberhardt K, Hafstrom I, Svensson B: Prediction of radiological outcome in early rheumatoid arthritis in clinical practice: role of antibodies to citrullinated peptides (anti-CCP). Ann Rheum Dis 2004, 63:1090-1095.

21. Bukhari M, Thomson W, Scott DGI, Symmons DPM, Silman AJ: Antibodies to cyclic citrillinated peptide and rheumatoid factor in early undifferentiated inflammatory arthritis: results from the Norfolk Arthritis Register. Rheumatology 2006, 45 (Suppl 1):i93.

22. Goodson NJ, Wiles NJ, Lunt M, Barrett EM, Silman AJ, Symmons DP: Mortality in early inflammatory polyarthritis: cardiovascular mortality is increased in seropositive patients. Arthritis Rheum 2002, 46:2010-2019.

23. Goodson N, Marks J, Lunt M, Symmons D: Cardiovascular admissions and mortality in an inception cohort of patients with rheumatoid arthritis with onset in the 1980s and 1990s. Ann Rheum Dis 2005, 64:1595-1601.

24. Marshall AT, Bunn DK, Symmons DPM, Harvey I, Shepstone L, Oakes S: Prevalence of self-reported angina in a communitybased inception cohort of patients with inflammatory arthritis [abstract]. Arthritis Rheum 2005, 52(Suppl):S329.

25. Franklin J, Lunt M, Bunn D, Symmons DPM, Silman A: Increased risk of lymphoma observed in a 10 year prospective study of a large primary-care based inception cohort of patients with inflammatory polyarthritis [abstract]. Arthritis Rheum 2005, 52 (Suppl):S264.

26. Wiles NJ, Lunt M, Barrett EM, Bukhari M, Silman AJ, Symmons DP, Dunn G: Reduced disability at five years with early treatment of inflammatory polyarthritis: results from a large observational cohort, using propensity models to adjust for disease severity. Arthritis Rheum 2001, 44:1033-1042.

27. Bukhari MA, Wiles NJ, Lunt M, Harrison BJ, Scott DG, Symmons $\mathrm{DP}$, Silman AJ: Influence of disease-modifying therapy on radiographic outcome in inflammatory polyarthritis at five years: results from a large observational inception study. Arthritis Rheum 2003, 48:46-53.

28. Hider SL, Lunt M, Bunn D, Manning S, Symmons DPM, Silman AJ: Can we predict the outcome of methotrexate treatment in inflammatory polyarthritis using clinical variables? Rheumato/ogy 2006, 45(Suppl 1):I54.

29. Harrison B, Thomson W, Symmons D, Ollier B, Wiles N, Payton T, Barrett E, Silman A: The influence of HLA-DRB1 alleles and rheumatoid factor on disease outcome in an inception cohort of patients with early inflammatory arthritis. Arthritis Rheum 1999, 42:2174-2183.

30. Goodson NJ, Tellam DJ, Barton A, Lunt M, Barrett EM, Silman AJ, Symmons DPM: HLA DRB1 shared epitope bearing alleles associated with RA disease severity also predict mortality in patients with inflammatory polyarthritis. Rheumatology (Oxford) 2003, 42 (Suppl 1):7.

31. Barton A, Platt $H$, Salway F, Symmons D, Barrett E, Bukhari M, Lunt $M$, Zeggini E, Eyre S, Hinks A, et al.: Polymorphisms in the tumour necrosis factor gene are not associated with severity of inflammatory polyarthritis. Ann Rheum Dis 2004, 63:280-284.

32. Barton A, Platt H, Salway F, Symmons D, Lunt M, Worthington J, Silman A: Polymorphisms in the mannose binding lectin (MBL) 
gene are not associated with radiographic erosions in rheumatoid or inflammatory polyarthritis. J Rheumatol 2004, 31:442-447.

33. Suzuki A, Yamada R, Chang X, Tokuhiro S, Sawada T, Suzuki M, Nagasaki M, Nakayama-Hamada M, Kawaida R, Ono M, et al:: Functional haplotypes of PADI4, encoding citrullinating enzyme peptidylarginine deiminase 4 , are associated with rheumatoid arthritis. Nat Genet 2003, 34:395-402.

34. Barton A, Bowes J, Eyre S, Symmons D, Worthington J, Silman A: Investigation of polymorphisms in the PADI4 gene in determining severity of inflammatory polyarthritis. Ann Rheum Dis 2005, 64:1311-1315

35. Ikari K, Kuwahara M, Nakamura T, Momohara S, Hara M, Yamanaka $\mathrm{H}$, Tomatsu T, Kamatani $\mathrm{N}$ : Association between PADI4 and rheumatoid arthritis: a replication study. Arthritis Rheum 2005, 52:3054-3057.

36. Kang $\mathrm{CP}$, Lee HS, Ju H, Cho H, Kang C, Bae SC: A functional haplotype of the PADI4 genen associated with increased rheumatoid arthritis susceptibility in Koreans. Arthritis Rheum 2006, 54:90-96.

37. Plenge RM, Padyukov L, Remmers EF, Purcell S, Lee AT, Karlson EW, Wolfe F, Kastner DL, Alfredsson L, Altshuler D, Gregersen PK, Klareskog L, Rioux JD: Replication of putative candidategene associations with rheumatoid arthritis in $>4000$ samples from North America and Sweden: association of susceptibility with PTPN22, CTLA4 and PADI4. Am J Hum Genet 2005, 77:1044-1060

38. Caponi L, Petit-Teixeira E, Sebbag M, Bongiorni F, Moscato S, Pratesi F, Pierlot C, Osorio J, Chapuy-Regaud S, Guerrin M, Cornelis F, Serre G, Migliorini P; ECRAF: A family based study shows no association between rheumatoid arthritis and the PADI4 gene in a white French population. Ann Rheum Dis 2005, 64:587-593. 